\title{
Perturbation of upper gastrointestinal transit and antroduodenal motility by experimentally applied stress: the role of beta-adrenoreceptor mediated pathways
}

\author{
J D O'BRIEN, D G THOMPSON, S J DAY, W R BURNHAM,
} AND E WALKER

From the Departments of Gastroenterology and Biometry, The London Hospital Medical College and Oldchurch Hospital, London

SUMMARY A series of three experiments were performed on healthy adult volunteers to investigate the possible role played by beta-adrenoreceptor mediated pathways in the disturbance of human upper intestinal motor function by hand immersion in cold water. In the first experiment, (an extended pilot study on one individual), orocaecal trarsit of a standard meal was measured on 36 occasions with and without cold water stimulation and with and without a series of $\alpha$ and $\beta$ blocking drugs. Cold water stimulation consistently delayed transit in this individual, an effect which was attenuated by prior $\beta$-blockade. In a double blind trial of the effect of $\beta$-blocker atenolol $v$ placebo on transit in nine individuals, a consistent reduction in the cold water induced transit delay was observed $(p<0.01)$ independent of any direct effect of beta-blockade. In the third experiment seven individuals underwent repeated studies of antroduodenal pressure activity comparing the effects of cold and warm water stimulation with and without beta blockade to determine whether the observed transit effect could be related to an action on gastrointestinal motility. Cold water stimulation reduced antroduodenal motility, but no consistent effects of previous beta blockade were noted. These studies indicate the presence of a beta-adrenoreceptor mediated pathway in the cold water induced delay of orocaecal transit but not in the inhibition of gastroduodenal motility. Further studies are indicated to determine the site and mode of action of this transit effect more precisely.

The human gastrointestinal tract is a complex selfregulating system controlling the delivery, digestion and elimination of nutrients through its lumen in a manner which remains virtually independent of any conscious process.

The higher centres, however, do modulate these autonomic functions to facilitate and inhibit the process of digestion. Facilitatory processes have been recognised since Pavlov' and the cephalic phase of digestion is now reasonably well understood. In contrast, the inhibitory effects of higher cortical centres on gut function remain poorly determined,

Address for correspondence: Dr D G Thompson, Department of Medicine. Hope Hospital, Eccles Old Road, Salford M6 8HD.

Accepted for publication 14 March 1989. despite the long held clinical suspicion that the psyche can interfere with the digestive function to cause symptoms and even organic disease..$^{23}$

Experimental disturbance of human upper gastrointestinal function has now been shown using a number of autonomic stimuli. ${ }^{+\infty}$ One commonly used stimulus has been discomfort induced by hand immersion in cold water, ${ }^{67}$ a technique previously used by cardiovascular physiologists as the "cold pressor test" ${ }^{\text {11 }}$ to probe the autonomic control of the heart and circulation. This stimulus is known to alter autonomic function through the central nervous system, inducing sympathetic stimulation and a rise in circulating concentrations of catecholamines. " When applied during studies of gastrointestinal 
function, it has been shown to delay gastric emptying, reduce gastric secretion and inhibit gastric antral motor activity." Transit of a non-absorbed carbohydrate from mouth to caecum, is also delayed.'"

Orocaccal transit, measured by breath hydrogen sampling, has several practical advantages for human experimentation. ${ }^{13}$ It is simple, cheap, non-invasive and free from irradiation which allows its repeated use in individuals without hazard. We therefore used a previously standardised version of this technique ${ }^{2}$ together with manometric studies to probe the possible role of sympathetic pathways in the cold water induced disturbances of upper gut function, and have found evidence for beta-adrenoreceptors in the mediation of this effect, independent of action on antral or duodenal motility.

\section{Methods}

SUBJECTS

Fifteen healthy adult volunteers (aged 18-54 years) without any history of gastrointestinal symptoms, took part in the series of studies described below, after first giving written informed consent. Prior approval for all experiments was obtained from the Ethics Committee of the London Hospital.

The studies were conducted as three experiments. The first two investigated the effects of cold water stimulation on orocaecal transit, the other used an intubation technique to examine the effects of cold water stimulation on antroduodenal motor activity.

OROCAECAL TRANSIT

Orocaecal transit was measured by serial exhaled breath hydrogen sampling,,$^{13}$ using a commercially available hydrogen sensitive electrochemical cell (GMI Ltd, Renfrew, Scotland). Subjects ingested a standard liquid mixed nutrient meal (chicken soup HJ Heinz Ltd, $400 \mathrm{ml} 255 \mathrm{kcal}$ ) to which $30 \mathrm{ml}$ lactulose solution (Duphalac, Duphar ple) was added as a transit marker. In previous studies ${ }^{12}$ this meal provided a reliable index of upper gastrointestinal transit with a mean time to onset of a sustained breath hydrogen rise of $64.0(3 \cdot 8)$ minutes (mean (SEM)) and a mean coefficient of variation for an individual of $9 \cdot 1 \%$, without the development of abdominal symptoms.

Before and during each study subjects avoided smoking, exercise and ingestion of confectionery, activities known to adversely affect the accuracy of hydrogen measurement. ${ }^{1+}$ All subjects fasted for at least 15 hours overnight to reduce basal hydrogen levels and studies were abandoned if preliminary breath hydrogen values exceed 20 parts per million $(\mathrm{ppm})$. As in previous studies ${ }^{2}$ serial samples of exhaled breath were provided by subjects at five minute intervals throughout each experiment and at two minute intervals once hydrogen values appeared to become raised.

\section{ANTRODUODENAI. MOTII.ITY}

After an overnight fast, subjects swallowed a multilumen tube which was guided with the aid of fluoroscopy so that its tip was in the proximal jejunum. The tube was constructed from a number of polyvinyl chloride tubes (id $0.63 \mathrm{~mm}$ ) bonded by tetrahydrofuran around a central radioopaque channel (id $3 \mathrm{~mm}$ ), which was interrupted at one point by a short radiolucent segment to allow its position to be fluoroscopically located at the pylorus. Six channels of the tube opened at $1 \mathrm{~cm}$ intervals, three on either side of the pyloric market to enable distal antral and proximal duodenal activity to be identified. A further channel opening at the tip of the tube enabled measurements to be made from the distal duodenum. Each channel was perfused with distilled water through a low compliance pneumohydraulic pump, intraluminal pressure change at each site being detected through attached strain gauge transducers (Gacltec Ltd S8b Dunvegan, Skye, Scotland). The output of each transducer was then fed into a multichannel chart recorder (Watanabe, Lincarcorder mk VII, Tokyo, Japan), run at a rate of $25 \mathrm{~mm} / \mathrm{min}$, to provide a permanent graphic record.

AUTONOMIC STIMULATION

Autonomic stimulation was started five minutes before meal ingestion as in earlier studies ${ }^{72}$ by repeated one minute immersions of the subjects nondominant hand in cold water, with 15 seconds recovery between immersions, and was continued for 20 minutes. For the control stimulus, water at $37^{\circ} \mathrm{C}$ was used. Autonomic responses to the test and control stimuli were assessed by serial measurements of brachial artery pressure (using a random zero sphygmomanometer) together with pulse rate (by radial artery palpation), while an individual's perception of discomfort on each occasion was graded on a simple linear scale ranging from 0 (complete comfort) to 10 (intolerable discomfort), termed the 'stress index'. Previous experience with the hand immersion technique ${ }^{7 !}$ has shown that the period of autonomic stimulation exceeds the period of hand immersion by approximately 10 minutes, as further discomfort occurs on hand rewarming.

\section{DRUGS}

All pharmacological agents used for the experiments were commercially available preparations obtained from the hospital pharmacy. The preparation of Lpropranolol used was Inderal $160 \mathrm{mg}$ (ICI plc). Sotalol was used in the form of Sotacor $160 \mathrm{mg}$ 
(Bristol-Myers), and atenolol as Tenormin $100 \mathrm{mg}$ (Stuart Pharmaceuticals Ltd) a dose which in man is highly beta-1 adrenoreceptor specific. ${ }^{15} \mathrm{D}$ propranolol tablets were obtained from ICI plc. Dummy tablets to match the atenolol were provided by the hospital pharmacy. Thymoxamine $(120 \mathrm{mg})$ was given as Opilon (Warner Ltd). All drugs were ingested one hour before the application of the test stimulus.

EXPERIMENTAL PROTOCOLS

Three different experiments were conducted as outlined below.

\section{Pilot study of the effects of adrenoreceptor}

blocking drugs on the cold water induced transit delay This study comprised 36 orocaecal transit experiments carried out on one individual after a standard protocol on each occasion (Fig. 1).

Drugs given were L-propranolol (a non-specific beta blocker with both central and peripheral actions), D-propranolol (which has membrane stabilising but not beta blocking action), sotalol (a non-specific peripherally acting beta blocker), atenolol (a beta-1 specific peripherally acting beta blocker), ${ }^{15}$ and thymoxamine (a non-specific alpha blocker).

Each drug was given on six separate occasions one hour before meal ingestion. On three occasions drug ingestion was followed by cold water hand immersion, on three others it was followed by warm water hand immersion, the overall order of experiments being randomised.

\section{Double blind, randomised controlled trial of atenolol $\mathrm{v}$ placebo on the cold water induced transit delay}

Based on the results of the pilot study, a double blind randomised trial was conducted to compare atenolol $v$ placebo on orocaecal transit during either cold water or warm water stimulation. Nine subjects underwent the four transit studies on separate days, the order of experiments being determined by a latin square design. Either atenolol or a matched dummy tablet was given one hour before each study.

3 Double blind trial of atenolol $\mathbf{v}$ placebo on the cold water induced alteration in antroduodenal motility

Seven subjects were studied on two days, two experiments being performed on each day in order to reduce the need for repeated intubation and $x$-ray exposure from four occasions to two. As the biological half life of atenolol ${ }^{15}$ exceeded the duration of a single study, it was not possible to use a fully balanced latin square experimental design; so a

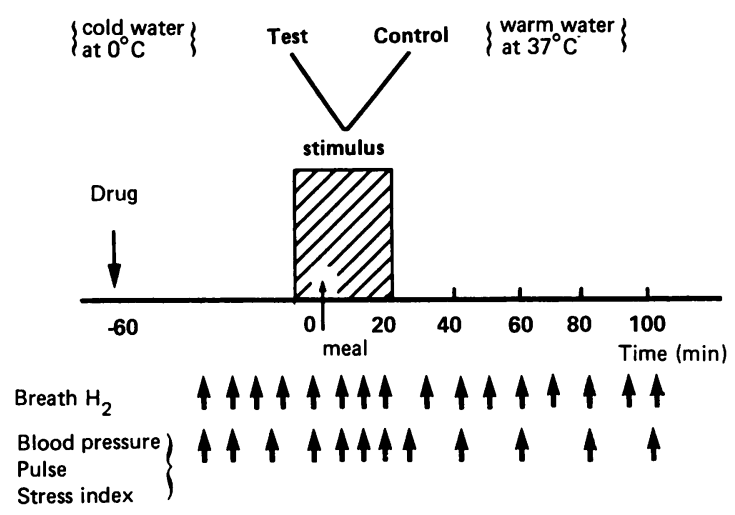

Fig. 1 This diagram summarises the experimental protocol used for all the transit studies performed in experiments $I$ and 2. Arrows indicate the time at which measurements were made, the hatched block indicates the time of application of the stimulus.

predetermined study order was designed by one of the authors (SJD) that allowed an adequate comparison of the four experimental conditions to be achieved without the possibility of beta-blocking effects spilling over into any succeeding placebo study (Table).

All subjects arrived in the laboratory after an overnight fast and ingested the multilumen tube. Once the tube was in situ, they rested quietly for a 30 min period. This allowed the subject to become familiar with the apparatus, and provided time for an assessment of the prevailing fasting motor pattern and measurement of resting pulse and blood pressure. The meal was then ingested during a period of phase II activity and 10 minutes were allowed to elapse, for antroduodenal motility to develop a fed pattern. The test or the control stimulus was then applied and changes in blood pressure, pulse and discomfort were assessed as in the other experiments.

Table Antroduodenal motility study

\begin{tabular}{|c|c|c|c|c|}
\hline \multirow[b]{3}{*}{ Subject } & \multicolumn{4}{|c|}{ Study order } \\
\hline & \multicolumn{2}{|c|}{ Day I } & \multicolumn{2}{|c|}{ Day 2} \\
\hline & $a m$ & $p m$ & $a m$ & $p m$ \\
\hline 1 & Pc & $\mathrm{Bc}$ & $\mathrm{Pw}$ & $\mathrm{Bw}$ \\
\hline 2 & $\mathrm{Pc}$ & $\mathrm{Pw}$ & $\mathrm{Bw}$ & $\mathrm{Bc}$ \\
\hline 3 & $\mathrm{Bw}$ & $\mathrm{Bc}$ & $\mathrm{Pc}$ & $\mathrm{Pw}$ \\
\hline 4 & $\mathrm{Pw}$ & $\mathrm{Bw}$ & $\mathrm{Bc}$ & $\mathrm{Bc}$ \\
\hline 5 & $\mathrm{Bc}$ & $\mathrm{Bw}$ & $\mathrm{Pw}$ & $\mathrm{Bc}$ \\
\hline 6 & $\mathrm{Pw}$ & $\mathrm{Pc}$ & $\mathrm{Pc}$ & $\mathrm{Bw}$ \\
\hline 7 & $\mathrm{Pc}$ & $\mathrm{Bc}$ & $\mathrm{Pw}$ & Pc \\
\hline
\end{tabular}

$\mathrm{P}=$ placebo $\mathrm{B}=$ beta blocker $\mathrm{c}=$ cold water $\mathrm{w}=$ warm water. 
In this experiment the stimulus was applied for 10 minutes, this duration being chosen to avoid unnecessary subject discomfort as pilot studies had indicated that the stimulus could rapidly induce changes in motility.

After completion of the first study, upper gastrointestinal motility was allowed to return to its fasting state, recognised by the return of a migrating burst of regular contractions (phase III). Another placebo or active tablet was then given and one hour later a second meal was ingested and the study repeated according to the predetermined study design. At the completion of the study the position of the tube in relation to the pylorus was rechecked by fluoroscopy before its removal to improve identification of antral and duodenal motor activity.

STATISTICAL ANALYSIS

For the purposes of data display group means and standard errors of the mean (SEM) have been used. For tests of significance, non-parametric comparisons of paired data were used with the technique of repeated measures analysis of variance, ${ }^{\text {th }}$ a $p$ value of $<0.05$ being taken to indicate a significant difference between pairs.

\section{EXTRAINTESTINAL RESPONSES}

Because previous studies ${ }^{712}$ indicated that the duration of discomfort after the cold water stimulus extended for about 10 minutes after cessation of the stimulus, the mean response for each autonomic variable in the transit studies was calculated for 30 minutes after its onset and compared with the mean value for the preceeding 30 minutes. The difference between these two values for the test and control

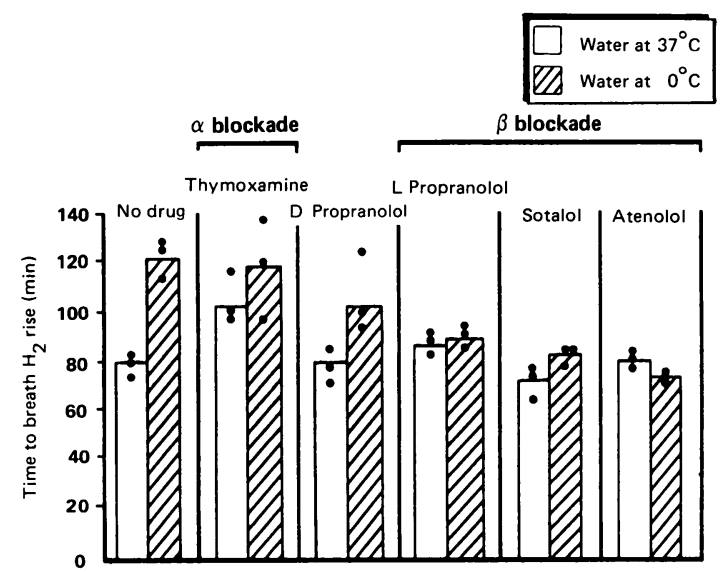

Fig. 2 The results of the 36 transit studies performed on one individual are shown. Each dot indicates the time of onset of a breath hydrogen rise for each transit study. The height of each column indicates the mean value for the three studies. studies was then used to indicate the magnitude of the extraintestinal response for that individual.

For the estimation of extraintestinal responses to the stimuli in the motility studies, the autonomic variables were measured over 20 minutes, and compared with the preceeding 20 minute period.

\section{OROCAECAL TRANSIT}

The arrival of the meal marker at the caecum was taken to have occurred at the onset of a rise in breath hydrogen. For the purpose of data analysis a hydrogen rise was defined as having occurred when the hydrogen concentration first exceeded twice the mean preingestion value. This method being chosen from previous studies 214 because it provided a simple but reliable end point.

ANTRODUODENAL MOTILITY

For the analysis of the pressure tracings a method previously described by others" was used. The channel closest to the pyloric marker which showed three per minute contractile activity was selected as the antral channel. The most proximal channel with consistent contractions at a frequency of approximately 12 per minute was chosen as the proximal duodenal channel. Channels closer to the pyloric marker in which this distinction could not be made were not studied. After channel selection, the number of pressure waves in the 10 minute periods before and during stimulation were counted and differences between these two values were used as an index of response to the stimulus. For analysis of distal duodenal activity the channel at the tip of the tube was always chosen.

To prevent the inclusion of artefact, only pressure activity equal to or greater than respiratory artefact was analysed, and activity occurring simultaneously in all channels, which may have been caused by transient intra-abdominal pressure change or tube movement, was excluded from analysis.

\section{Results \\ EXPERIMENT 1 PILOTSTUDY}

\section{Orocaecal transit}

The results of the 36 studies are summarised in Figure 2.

Cold water consistently delayed transit compared with control stimulation (control: $87.9(2.6) \mathrm{min} v$ test: $123 \cdot 4(2 \cdot 8)$ min, $\mathrm{p}<0 \cdot 05)$. Alpha adrenoreceptor blockade with thymoxamine did not alter this pattern of response. In contrast, L-propranolol and the other beta adrenoreceptor blockers consistently attenuated the cold water effect on transit whereas D-propranolol showed no such effect. 

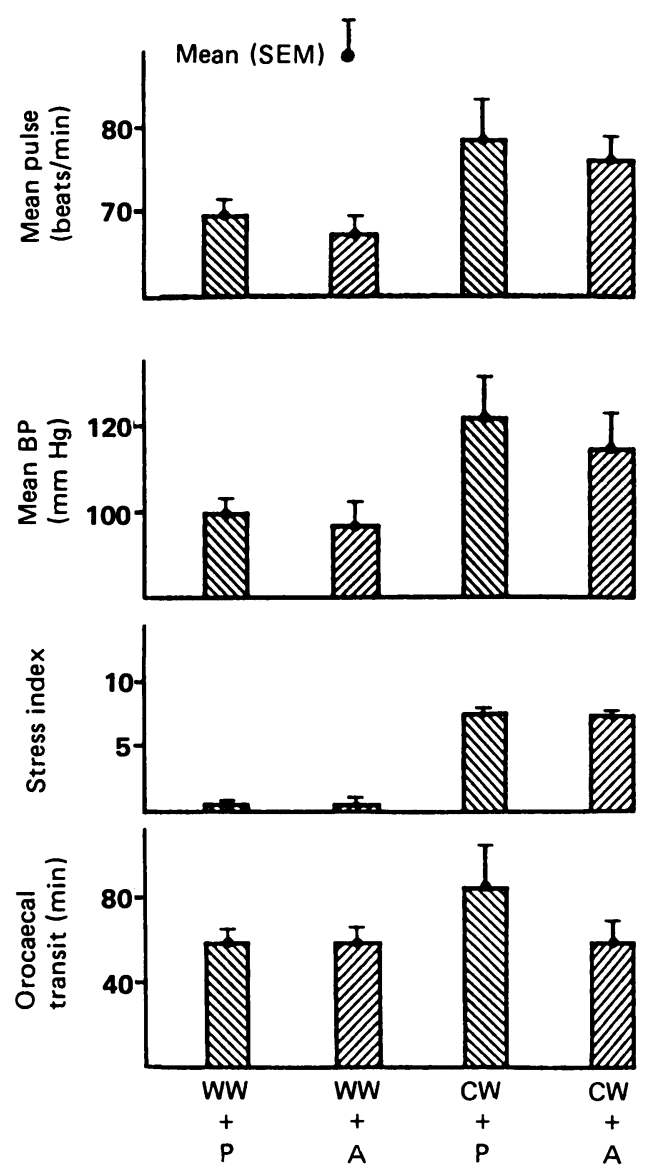

Fig. 3 The results of experiment 2 are summarised in this figure. $W W=$ warm water stimulation, $C W=$ cold water stimulation, $P=$ placebo, $A=$ atenolol.

\section{Extraintestinal reponses}

Cold water stimulation produced a consistent rise in systolic pressure (mean rise 25.1 (1.9) $\mathrm{mmHg}$, $\mathrm{p}<0.05)$ and diastolic pressure $(19 \cdot 1(1.1) \mathrm{mmHg}$, $\mathrm{p}<0.05)$, compared with control studies. The pulse rate increased by $5.3(0.8)$ beats/min $(\mathrm{p}<0.05)$ and the test stimulus was consistently regarded as unpleasant (change in stress index; $8.4(0 \cdot 1)$, $\mathrm{p}<0.05)$. There was no reduction in autonomic response between the first and last placebo cold water study (mean change in systolic BP; 1st $v 3 \mathrm{rd}, 23.0 v$ $24.7 \mathrm{mmHg}$ ), indicating that adaptation to the stimulus had not occurred.

\section{EXPERIMENT 2}

\section{Orocaecal transit}

The results of this study are shown in Figure 3.
In eight of the nine subjects cold water stimulation delayed transit, while in the other, there was little change (warm water transit: $58.5(3.6)$ mins $v$ cold water transit: $82 \cdot 2(8 \cdot 3) \mathrm{min}, \mathrm{p}<0 \cdot 01)$. Prior administration of atenolol significantly attenuated the cold water delay (placebo+cold water: $82.2(8.3) \mathrm{min} v$ atenolol+cold water: $56 \cdot 7(4 \cdot 4)$ min, $\mathrm{p}<0 \cdot 01)$. Atenolol ingested before warm water stimulation exerted no significant effect on transit (atenolol+ warm water: $56.0(3.7) v$ placebo+warm water: 58.5 $(3 \cdot 6), \mathrm{p}>0 \cdot 1)$.

\section{Extraintestinal responses}

During control stimulation the effect of beta blockade was apparent with a significant $(\mathrm{p}<0 \cdot 05)$ reduction in resting pulse rate (mean reduction 4.2 $(1.6)$ beats $/ \mathrm{min}$ ) and blood pressure (mean reduction in systolic pressure compared with placebo 5.6 (1.0 $\mathrm{mmHg}$ ). Cold water stimulation during placebo treatment produced the expected pressor response, with a mean rise in systolic blood pressure of 20.5 $(2.2) \mathrm{mmHg}(\mathrm{p}<0.01)$ and a mean diastolic rise of $17.7(0.9) \mathrm{mmHg}(\mathrm{p}<0.01)$. In addition the pulse rate rose (mean change $6.6(1.1)$ beats/min, $\mathrm{p}<0.01$ ) and the stimuus was consistently regarded as unpleasant (mean change in stress index $7.5(0.7), \mathrm{p}<0.01)$. Prior administration of atenolol reduced the magnitude of the cold water induced pressor and pulse responses when compared with placebo pretreatment but the absolute changes in the pulse and blood pressure between the two atenolol studies were similar to those of the two placebo experiments, indicating that previous beta blockade inhibited neither the cardiovascular autonomic responses, nor the perception of the discomfort.

\section{EXPERIMENT 3}

\section{Antroduodenal motility}

The results of this study are shown in Figures 4 and 5 .

Test meal ingestion produced a change from fasting (phase II activity) to a characteristic fed pattern on all occasions. This was recognised by a gradual reduction in the frequency of recordable antral contractions and an increase in the frequency of irregular duodenal contractions. In one individual, however, cold water stress interrupted the fed pattern of motility and induced the occurrence of a pattern resembling phase III activity. Atenolol alone or in the presence of stress did not cause any apparent change in the fed pattern.

For the group, cold water immersion after placebo reduced the number of pressure waves recorded from both antrum and duodenum an effect that reached significance in the antrum (mean reduction $11(2 \cdot 6)$ contractions $/ 10 \mathrm{~min}, \mathrm{p}<0.05)$ and distal duodenum 

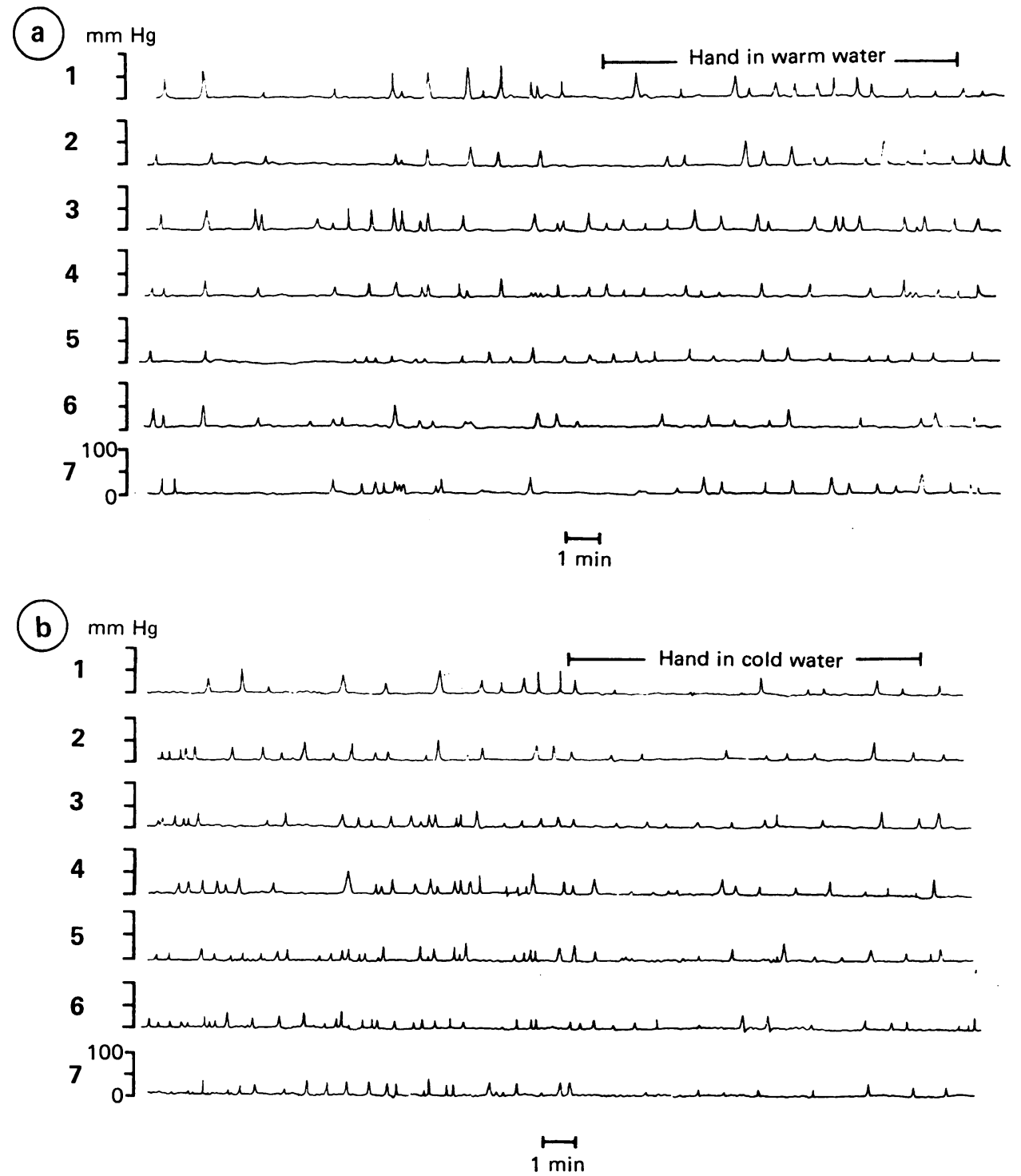

Fig. 4a, 4b Motility tracings from the same individual are shown both before and during control stimulation with warm water (Fig. 4a) and test stimulation with cold water (b). In both figures, each horizontal line shows intraluminal pressure activity from the antrum (channels 1-3), upper duodenal (channels 4-6), lower duodenum (channel 7). After cold water stimulation a reduction in motor activity can be seen in all channels.

(mean reduction $10 \cdot 6(3 \cdot 1)$ contractions $/ 10 \mathrm{~min})$. In the proximal duodenum a smaller more variable inhibition in motor activity was induced (mean reduction $4 \cdot 5(4 \cdot 0), p>0 \cdot 1)$. In contrast to the transit experiments, pretreatment with atenolol exerted no significant effect on motility during either test or control stimulation.

Because of the necessarily incomplete balance of the study, the presence of an order effect was sought by analysis of variance. No indication of any order effect was found.

\section{Extraintestinal responses}

As in the previous studies, cold water stimulation produced a consistent pressor response, with similar changes in systolic pressure $(18.8(2 \cdot 1) \mathrm{mmHg})$, and 
pulse $(6.8(1.4)$ beats/min) compared with warm water immersion. In all the control experiments atenolol was again associated with a significant fall in blood pressure (mean systolic reduction: $5.9(1.6)$ $\mathrm{mmHg}$ ) and pulse $(4.6(1.4)$ beats/min), compared with placebo, indicating again that the drug achieved beta blockade in all subjects. During cold water stimulation comparisons between the atenolol pair and the placebo pair also showed changes in blood pressure pulse, and discomfort comparable with the transit experiments indicating that the drug had neither abolished the cardiovascular responses to the
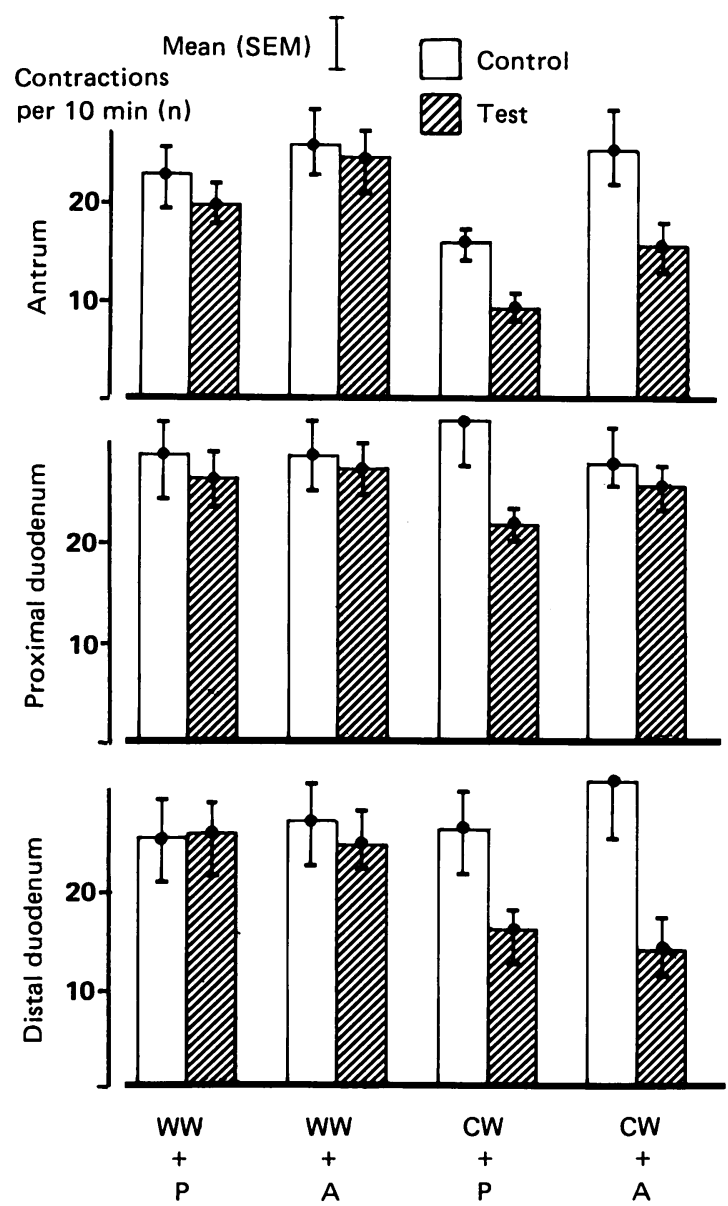

Fig. 5 This diagram shows the motor activity in the antrum and in the proximal and distal duodenum, during the four experiments. The prestimulation control period data are shown as open columns and the stimulation period data as hatched columns. Cold water stimulation can be seen to reduce both antral and duodenal motor activity, a response unaffected by prior Atenolol administration. See Figure 3 for code to columns. stimulus nor reduced the perception of discomfort experienced. In the four experiments in which atenolol was given twice on one day, no further reduction in blood pressure or pulse were measurable after the second dose, suggesting that the level of beta blockade had not altered and that effective beta blockade had been achieved by the initial dose.

Because of this apparent lack of effect of atenolol $\left(B_{1}\right)$, a series of repeat studies were performed on three subjects using propranolol $\left(\mathrm{B}_{1}\right.$ and $\mathrm{B}_{2}$ antagonist). The effects of propranolol on the cardiovascular and motility responses to cold immersion were very similar to those of atenolol, with no noticeable attenuation of the motor inhibition, indicating that neither beta 1 nor beta 2 receptors were likely to be mediating the response.

\section{Discussion}

The results of our studies, which show an overall inhibition of upper gut function in response to cold water stimulation, are consistent with previous reports of a general inhibitory effect of sympathetic stimulation on gut function ${ }^{17 / x}$ and with previous studies of the effects of cold water stimulation on human orocaecal transit. "It remains uncertain from our studies, however, whether the site of action of the sympathetic stimulus is gastric or small intestinal, or both. Certainly gastric emptying is delayed by cold stress $^{7}$ and by $\beta$ adrenoreceptor stimulation, ${ }^{1 "}$ but more recent studies also indicate similar actions of adrenoreceptor stimulation on duodenocaecal transit."

Sympathetic nervous stimulation is well recognised to cause inhibition of gut function in vitro ${ }^{17}$ and the anatomic pathways by which such inhibition is conveyed to the gut are known in some detail."2:2 The pharmacology of the system, however, particularly in man, is poorly defined. Such evidence which does exist suggests that the predominant receptor subtype on mammalian enteric ganglia is alpha specific ${ }^{17}$ whereas beta receptors seem to predominate on human gut smooth muscle. ${ }^{33}$

More recent developments in beta receptor research also show specific localisation, with beta-1 receptors being largely on the target organ, while beta- 2 receptors are largely prejunctional, on the nerve endings. ${ }^{2+}$ Beta receptors also show different affinities for catecholamines. Noradrenaline as might be expected is largely $\alpha 1$ and $\beta 1$ while adrenaline has greater $\alpha 2$ and $\beta 2$ potency,,- consistent with the concept that the former acts as a direct neurotransmitter while the latter is a more indirect neuromodulator.

In seeking to explain our finding of discrepant $\beta$ blockages effects on transit and antroduodenal 
motility, a number of possibilities arise. From the above data on $\beta$-receptor localisation and effect, one plausible explanation is that the noradrenergic stimulus provided by hand immersion in cold water, inhibited both smooth muscle and enteric neurone activity. The preferential localisation of beta receptors on smooth muscle rather than ganglia might suggest that the effect of cold water stress on intestinal transit is mediated by reduction in contractile force rather than a change in the pattern of contractile activity which is modulated by alpha receptors.

This hypothesis might also explain the report of reversal of cold stress mediated antral motor inhibition by combined alpha and beta blockade ${ }^{26}$ but not by beta blockade alone.

An alternative possibility to explain our results might be that a $\beta$-blockade effect on motility could be present in the gut, but at a site other than the antroduodenum. This hypothesis is consistent with data on feline intestinal motility showing that the ileum is more sensitive than the jejunum to the inhibitory effect of splanchnic stimulation. ${ }^{27}$ Furthermore splanchnic nerve section results in greater motor response in the ileum than jejunum ${ }^{27}$ suggesting that it is the lower rather than the upper small intestine which is under greatest sympathetic inhibitory control.

It has also be be accepted that serial antroduodenal intraluminal pressure measured by the technique used by us do not provide precise information about transport of intraluminal contents. Movement of nutrients through the stomach and intestine is the result of aboral pressure gradients induced by differential smooth muscle tone and aborally propagating peristaltic contractions. Measurement of these factors requires other more sophisticated methods for example, a barostat technique for tone measurement $^{2 \mathrm{x}}$ and multiple closely spaced sensors and fluoroscopy for direct measurement of intraluminal transport..$^{24}$ Because our measurements of motility were relatively crude, it is possible that betablockade could have altered transit through an action on the pattern of propagated contractions without being detected by our method. Further studies of motor responses to stress with and without betablockade using these more sophisticated techniques are obviously indicated.

In an earlier study' of cold stress effects on the gut, no consistent effects on antroduodenal motor activity were noted, a finding which contrasts with our data. While it is difficult to determine the exact reason for the discrepancy between those results and our current data, most plausible explanation relates to differences in methods of study and data analysis used. In the original experiment, hand immersion was continued for 20 minutes and measurements of motor activity were made for the duration of the stress period. In the present study a 10 minute stimulus was used, because preliminary studies indicated that the motility inhibition was short lived and motor activity returned to its usual irregular postprandial pattern within a few minutes of stimulus application. The earlier study may thus have missed an effect by including irrelevant independently variable data in the analysis.

A further possible explanation for our findings could be that the reduction of effect of cold water on transit after beta-blockade is mediated by a mechanism independent of motility. Other known effects of sympathetic stimulation on upper gut function include inhibition of gastric, pancreatic, and intestinal secretion. ${ }^{731}$ In each instance evidence exists to indicate a role for a beta adrenoreceptor mediated pathway in their inhibition. ${ }^{19.3132}$ It is possible, therefore, that present observations might also have occurred via such a pathway. Morris and Turnberg" showed a reduction in fasting small bowel fluid absorption after propranolol, suggesting that the sparing effect of beta blockade on stress induced transit delay might additionally be through inhibition of meal absorption. The failure of our warm water stimulation experiments to show a significant difference between placebo and atenolol groups, however, indicates that any intrinsic effect of beta blockade on orocaecal transit is likely to be small in comparison with cold water induced actions.

Because blood concentrations of atenolol were not measured it could be suggested that the failure to show a drug effect in the motility study might be a result of delayed gastric emptying and absorption, which has been reported to occur in the presence of an intestinal tube. ${ }^{33}$ This suggestion seems unlikely however, as pulse and blood pressure responses were equal in magnitude and speed of onset, in the motility and the transit studies. The rapidity of the response to atenolol administration is also consistent with data on its bioavailability. After an oral dose between 40$60 \%$ is absorbed ${ }^{153}$ and the percentage absorbed one hour after oral administration is at least $20 \% .{ }^{35}$ In addition, drugs which delay gastric emptying - for example, propantheline are reported to improve rather than decrease the bioavailability of atenolol, ${ }^{36}$ probably the result of more efficient dissolution of the tablet by increased contact with gastric juice.

While it is tempting to extrapolate the results of our studies into clinical practice and to explain gut dysfunction in patients in terms of sympathetic overactivity, caution must prevail. It has to be accepted that hand immersion in cold water while proving a valuable experimental stimulus to the sympathetic nervous system must be regarded as a physiologic 
'probe' and may not induce changes in gut physiology which mirror those produced by the more common stressors of day to day life. Our studies do, however, appear to have uncovered a gut control system mediated by a beta sympathetic pathway which seems hitherto virtually unexplored. Further study of its relevance for modulation of nutrient transit and absorption both under normal pathological conditions is now indicated.

Dr D G Thompson was a Wellcome Trust Senior Lecturer in Medicine.

\section{References}

1 Pavlov IP. Work of the digestive glands. Translated by WH Thompson. New York: Charles Griffin, 1910.

2 Beaumont W. Experiments and observations on the gastric juice and the physiology of digestion. Plattsburgh: FP Allen, 1833.

3 Wolf S, Wolff HG. Human gastric function. New York: Oxford Univ Press, 1943.

4 Cann PA, Read NW, Cammack J, et al. Psychological stress and the passage of a standard meal through stomach and small intestine in man. Gut 1983; 24: 23640.

5 Camilleri M, Malagelada JR. Stress-induced suppression of antral motility in functional dyspepsia [Abstract]. Gut 1984; 25: A1137.

6 Thompson DG, Richelson E, Malagelada JR. Perturbation of gastric emptying and duodenal motility through the central nervous system. Gastroenterology 1982; 73: $1200-6$.

7 Thompson DG, Richelson E, Malagelada JR. Perturbation of upper gastrointestinal function by cold stress. Gut 1983; 24: 277-83.

8 Erckenbrecht JR, Ziemer B, Lesch M, et al. Effect of long term mental stress by noise on transit of a meal through the small and large bowel [Abstract]. Gut 1984; 25: A1311.

9 Hines EA, Brown GE. A standard stimulus for measuring vasomotor reactions. Its application in the study of hypertension. Proc Staff Meet Mayo Clinic 1932; 7: 332-5.

10 Wolff $\mathrm{HH}$. The mechanism and significance of the cold pressor response. $Q J$ Med $1951 ; 20$ : 261-73.

11 Stanghellini V, Malagelada JR, Zinsmeister AR, Go VLW, Kao PC. Stress induced gastroduodenal motor disturbance in humans; possible humoral mechanisms. Gastroenterology 1983; 85: 83-91.

12 O'Brien JD, Thompson DG, Burnham WR, Holly J, Walker E. The action of central mediated autonomic stimulation on human upper gastrointestinal transit: a comparative study of two stimuli. Gut 1987; 28: 960-9.

13 Bond $\mathrm{JH}$, Levitt MD. Investigation of small bowel transit time in man utilizing pulmonary hydrogen $(\mathrm{H} 2)$ measurements. J Lab Clin Med 1975; 85: 546-55.

14 Thompson DG, Binfield P, De Belder A, O'Brien J, Warren $S$, Wilson $M$. Extraintestinal influences on exhaled breath hydrogen measurement during the investigation of gastrointestinal disease. Gut 1985; 26: 1349-52.

15 Barrett AM. The pharmacology of Atenolol. Postgrad Med J 1977; 53 (suppl 3): 58-64.

16 Armitage P. Statistical methods in medical research. London: Blackwell, 1977.

17 Gillespie JS, Khoyi MA. The site and receptors responsible for the inhibition of sympathetic nerves of intestinal smooth muscle and its parasympathetic motor nerve. J Physiol (Lond) 1977; 267: 767-89.

$18 \mathrm{Ek} \mathrm{B}$, Lundgren B. Characterization of beta adrenoreceptors mediating the inhibition of spontancous contractile activity in isolated cat colon strips. Acta Physiol Scand 1979; (suppl 473): 43.

19 Rees MR, Clark RA, Holdsworth CD, Barber DC. Howlett PJ. The effect of beta adrenoreceptor agonists and antagonists on gastric emptying in man. $\mathrm{Br} \mathrm{J}$ Pharmacol 1980; 10: 551-4.

20 O’Brien JD, Thompson DG, Holly J, Burnham WR, Walker E. Stress disturbs human gastrointestinal transit via a beta 1 adrenoreceptor mediated pathway. Gastroenterology 1985; 88: 1520 .

21 Furness JB, Costa $M$. The adrenergic innervation of the gastrointestinal tract. Ergeb Physiol 1974; 69: $1-52$.

22 Llewellyn-Smith IJ, Furness JB, O`Brien PE. Costa M. Noradrenergic nerves in human small intestine, distribution and ultrastructure. Gastroenterology 1984: 87: 51329.

23 Hedges A. Turner P. Beta receptors in human isolated smooth muscle. Br J Pharmacol 1969; 37: 547-8.

24 Broadley KJ. Chess-Williams R. Grassby P. A physiological basis for subclassifying $\beta$-adrenoreceptors examined by chemical sympathectomy of guinea pigs. J Physiol 1986; 373: 367-78.

25 Ariens EJ, Simonis A. Physiological and pharmacological aspects of adrenergic receptor classification. Biochem Pharmacol 1983; 22: 1539-45.

26 Stanghellini V, Malagelada J-R, Zinsmeister AR, Go VLW, Kao PC. Effect of opiate and adrenergic blockers on the gut motor response to centrally acting stimuli. Gastroenterology 1984; 87: 1104-13.

27 Kewenter J. The vagal control of the jejunal and ileal motility and blood flow. Acta Physiol Scand 1965; 65 (suppl 251): ??.

28 Azpiroz F. Malagelada J-R. Gastric tone measured by an electronic barostat in health and postsurgical gastroparesis. Gastroenterology 1987; 92: 934-43.

29 Schemann M. Ehrlein H-J. Postprandial patterns of canine jejunal motility and transit of luminal content. Gastroenterology 1986; 90: 991-1000.

30 Barclay GR, Turnberg LA. Influence of physical and psychological stress on fluid and electrolyte absorption in the human jejunum in vivo. Gut 1985; 26: 554.

31 Morris AI, Turnberg LA. Influences of isoproterenol and propranolol on human intestinal transport in vivo. Gastroenterology 1982; 81: 1076-9.

32 Kelly GA, Rose RC, Nahrwold DL. Characteristics of inhibition of pancreatic secretion of isoproterenol. Surgery 1977; 82: 680-4.

33 Read NW, Al Janabi MN, Bates TE, Barber DC. Effect 
of gastrointestinal intubation on the passage of a solid meal through stomach and small intestine in humans. Gastroenterology 1983; 84: 1568-72.

34 Brown HC, Carruthers SG, Johnston GD, et al. Clinical pharmacologic observations on atenolol, a beta adrenoreceptor blocker. Clin Pharmacol Ther 1976; 20: 52434.
35 Mason WD. Winer N. Kochak BS. Cohen I. Bell R. Kinctics and absolute bioavailability of atenolol. Clin Pharmacol Ther 1979; 25: 408-15.

36 Regardh CG, Lundborg P. Persson BA. The effect of antacid. metoclopramide and propantheline on the bioavailability of Metoprolol and Atenolol. Biopharm Drug Dispos 1981; 2: 79-87. 